\title{
Transparent Phosphorus Doped ZnO Ohmic Contact to GaN Based LED
}

\author{
Jae-Hong Lim ${ }^{\dagger}$ and Seong-Ju Park* \\ Department of Chemical \& Environmental Engineering, University of California, Riverside, California 92521 \\ *Department of Materials Science and Engineering, Gwangju Institute of Science and Technology, \\ Gwangju 500-712, Korea
}

(Received June 20, 2009 : Received in revised form July 27, 2009 : Accepted August 4, 2009)

\begin{abstract}
This study develops a highly transparent ohmic contact using phosphorus doped $\mathrm{ZnO}$ with current spreading for $\mathrm{p}$ $\mathrm{GaN}$ to increase the optical output power of nitride-based light-emitting diodes (LEDs). The phosphorus doped ZnO transparent ohmic contact layer was prepared by radio frequency magnetron sputtering with post-deposition annealing. The transmittance of the phosphorus doped $\mathrm{ZnO}$ exceeds $90 \%$ in the region of $440 \mathrm{~nm}$ to $500 \mathrm{~nm}$. The specific contact resistance of the phosphorus doped $\mathrm{ZnO}$ on p-GaN was determined to be $7.82 \times 10^{-3} \Omega \cdot \mathrm{cm}^{2}$ after annealing at $700{ }^{\circ} \mathrm{C}$. GaN LED chips with dimensions of $300 \times 300 \mu \mathrm{m}$ fabricated with the phosphorus doped $\mathrm{ZnO}$ transparent ohmic contact were developed and produced a $2.7 \mathrm{~V}$ increase in forward voltage under a nominal forward current of $20 \mathrm{~mA}$ compared to GaN LED with Ni/Au Ohmic contact. However, the output power increased by $25 \%$ at the injection current of $20 \mathrm{~mA}$ compared to GaN LED with the Ni/Au contact scheme.
\end{abstract}

Key words phosphorus doped $\mathrm{ZnO}$, ohmic contact, GaN LED.

\section{Introduction}

$\mathrm{GaN}$ and related compounds are attractive materials for optoelectronic devices in the blue and ultraviolet spectral region. ${ }^{1-3)}$ However, low contact resistance and low transmission efficiency reduce the overall performance of these electronic and optical devices. Especially, the fabrication of high-quality ohmic contacts with low resistance, thermal stability, and high transparency, is of great technological importance for the optical device applications. Currently, it is hard to grow heavily doped p-GaN $\left(>10^{18} \mathrm{~cm}^{-3}\right)$ and there is no appropriate metal with a work function larger than that of $\mathrm{GaN}(\sim 7.5 \mathrm{eV})$. Thus, oxidizing $\mathrm{Ni} / \mathrm{Au}$ thin film is commonly used as the ohmic contact to $\mathrm{p}-\mathrm{GaN}^{4,5)}$ The main concept is to use $\mathrm{p}-\mathrm{NiO}$ with nickel vacancies and/or oxygen interstitials contacts to $\mathrm{p}-\mathrm{GaN}$ to reduce interface resistance. However, the Au-based contacts generally have poor thermal stability, leading to poor device reliability. Recently, Ni/ITO thin film shows the low resistance and transparent ohmic contact to p-GaN. ${ }^{6}$

In other hands, $\mathrm{ZnO}$, an optically transparent material, is widely used in various applications, including light-emitting diodes (LED), flat-panel displays, and solar cells. Recently, we reported on the successful growth of phosphorus doped

${ }^{\dagger}$ Corresponding author

E-Mail : limjh92@gmail.com (J. -H. Lim)
$\mathrm{p}-\mathrm{ZnO}$ with a high hole concentration $\left(>10^{18} \mathrm{~cm}^{-3}\right) .^{7,8)}$ The phosphorus doped $\mathrm{ZnO}$ can be used as the transparent ohmic contact layer due to its high carrier concentration and high transparency. In this study, we report on the development of GaN LED chips with a phosphorus doped p-ZnO transparent ohmic contact.

\section{Experimental Procedure}

The MQW samples were grown on c-plane sapphire substrates using metallorganic vapor deposition in a rotating disk reactor (Emcore D125). The LED structures consisted of a GaN nucleation layer, a Si-doped n-GaN layer, five periods of $\mathrm{InGaN} / \mathrm{GaN}$ MQW active layer, and a Mgdoped $\mathrm{p}-\mathrm{GaN}$ capping layer. A detailed description of the growth procedures was provided elsewhere. ${ }^{9)}$ To investigate the effect of a phosphorus doped $\mathrm{ZnO}$ transparent ohmic contact layer on electrical and optical performance of LEDs, two types of LED chips each with an area of $300 \times 300 \mu \mathrm{m}$ were fabricated as follows. The surface of the p-type GaN layer was partially etched using an inductively coupled $\mathrm{CH}_{4} / \mathrm{Cl}_{2} / \mathrm{H}_{2} / \mathrm{Ar}$ plasma until the n-GaN layer was exposed. A Ti/Al $(30 \mathrm{~nm} / 80 \mathrm{~nm})$ film was deposited on the n-type $\mathrm{GaN}$ layer via e-beam evaporation, and a $\mathrm{Ni} / \mathrm{Au}$ film of $3 \mathrm{~nm} / 8 \mathrm{~nm}$ in thickness by e-beam evaporation and a phophorus doped $\mathrm{ZnO}$ of $250 \mathrm{~nm}$ in thickness by radio frequency sputtering, respectively, were deposited 
onto the p-GaN layer as the current spreading layer. ${ }^{7)}$ Finally, Ni/Au (30 nm/80 nm) was subsequently evaporated on the current spreading layer as the top electrode. These metals were patterned by a standard metal lift-off technique. Prior to the metal deposition, the samples were cleaned in a buffered oxide etchant (BOE) solution. This step was found to greatly enhance the adhesion of metal layers by removing oxides from the surfaces of the exposed $\mathrm{GaN}$. All metal contacts were annealed at $500{ }^{\circ} \mathrm{C}$ for $30 \mathrm{~s}$ under a $\mathrm{N}_{2}$ gas ambient. A phophorus doped $\mathrm{ZnO}$ was annealed at $600{ }^{\circ} \mathrm{C}$ for 1 min under a $\mathrm{N}_{2}$ gas ambient. For the electrical and optical characteristics of the MQW LED, the current-voltage (I-V) and the electroluminescence (EL) measurements were performed at room temperature. The inner dot radius was $200 \mu \mathrm{m}$ and the spacing between the inner and the outer radii varied from 5 to $50 \mu \mathrm{m}$. To characterize the extent of inter-diffusion between the $\mathrm{p}-\mathrm{ZnO}$ layer and the p-GaN film, Auger electron spectroscopy (AES) analysis was performed using a PHI 670 Auger microscope with an electron beam energy of $10 \mathrm{keV}$ and a current of $0.029 \mu \mathrm{A}$. X-ray photoemission spectroscopy (XPS) was carried out using an $\mathrm{Al} K \alpha$ X-ray source in XPS system (PHI 5200 model).

\section{Results and discussions}

Fig. 1(a) shows the current-voltage $(I-V)$ characteristics of the $\mathrm{p}-\mathrm{ZnO}$ contact layers on $\mathrm{p}-\mathrm{GaN}$, measured between ohmic pads with a spacing of $50 \mu \mathrm{m}$. The $\mathrm{p}-\mathrm{ZnO}$ contact shows good ohmic contact to $\mathrm{p}-\mathrm{GaN}$ after the annealing at $700{ }^{\circ} \mathrm{C}$ for $1 \mathrm{~min}$ under a nitrogen ambient. Even though $\mathrm{ZnO}$ : $\mathrm{P}$ annealed at $900{ }^{\circ} \mathrm{C}$ shows highest electrical properties (hole concentration and mobility), ${ }^{7)}$ the contact property degraded after the annealing at $900{ }^{\circ} \mathrm{C}$ for $1 \mathrm{~min}$ under a nitrogen ambient. This might be attributed to the oxygen in-diffusion in to $\mathrm{p}-\mathrm{GaN}$ to form gallium oxide at the interface. When surface oxides exist on $\mathrm{p}-\mathrm{GaN}$, holes in valence band are trapping into deep levels in the oxides because surface oxides have a number of defects. The $\mathrm{p}$ $\mathrm{ZnO}$ contact exhibited a linear ohmic behavior in the voltage range of $-2 \sim 2 \mathrm{~V}$. The specific contact resistance was calculated from plots of the measured resistances versus the spacings between the c-TLM pads. The specific contact resistance was determined to be $7.82 \times 10^{-3} \Omega \cdot \mathrm{cm}^{2}$ after the annealing at $700{ }^{\circ} \mathrm{C}$, indicating that the $\mathrm{p}-\mathrm{ZnO}$ can be used as a good ohmic scheme for $\mathrm{p}-\mathrm{GaN}$. The light transmittance of the annealed $\mathrm{p}-\mathrm{ZnO}$ was measured and the values were found to be above $90 \%$ in the region of $440 \mathrm{~nm}$ to $500 \mathrm{~nm}$ due to the large bandgap of $\mathrm{ZnO}(3.3 \mathrm{eV}$ at room temparature). ${ }^{10)}$ The reason why we adopted a nitrogen ambient was that during the annealing process, phosphorus oxide supplies two phosphorus atoms acting as acceptors and five oxygen atoms which may compensate oxygen vacancies that act as donors. ${ }^{7)}$

In-depth Auger profiles of the $\mathrm{p}-\mathrm{ZnO}$ contact layers on $\mathrm{p}-\mathrm{GaN}$ before and after the annealing process are shown in Fig. 2. Almost no reaction occurred at the interface between $\mathrm{GaN}$ and $\mathrm{ZnO}$ after the annealing comparing to the as-deposited $\mathrm{p}-\mathrm{ZnO}$ on $\mathrm{p}-\mathrm{GaN}$. It indicates that deep levels to trap holes at the interface are not formed by the diffusion.

To characterize the chemical bonding state of $\mathrm{P}$ and $\mathrm{O}$ atoms in $\mathrm{p}-\mathrm{ZnO}$ ohmic schemes, XPS analysis was performed on the ohmic contact layers on the $\mathrm{p}-\mathrm{GaN}$, after annealing in a nitrogen ambient. P $2 p$ core-level peak observed

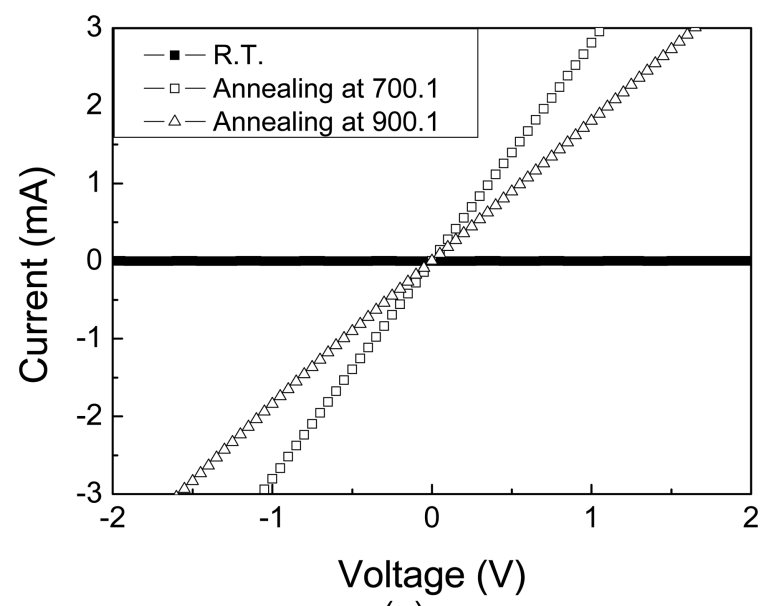

(a)

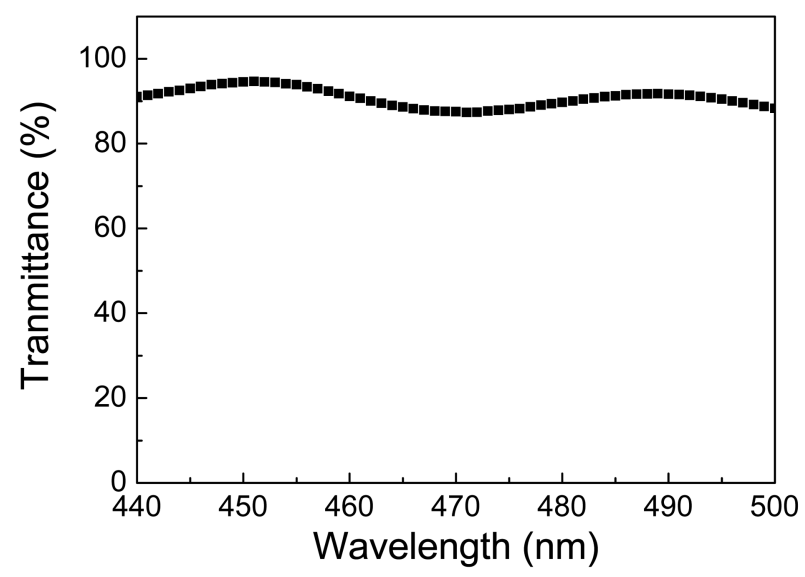

(b)

Fig. 1. (a) $\mathrm{I}-\mathrm{V}$ characteristics of the $\mathrm{p}-\mathrm{ZnO}$ contacts to $p-\mathrm{GaN}$ before and after different annealing processes. (b) The light transmittance for a $\mathrm{p}-\mathrm{ZnO}$ sample annealed at $700{ }^{\circ} \mathrm{C}$ for $1 \mathrm{~min}$. 


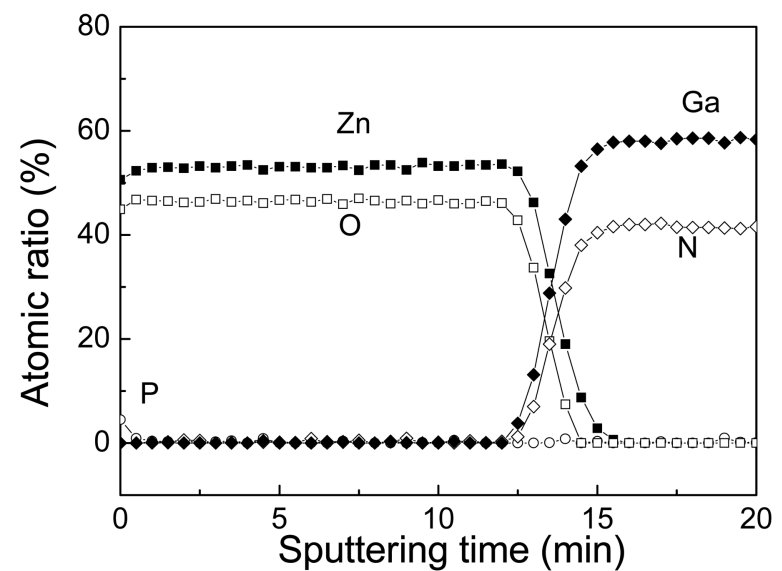

(a)

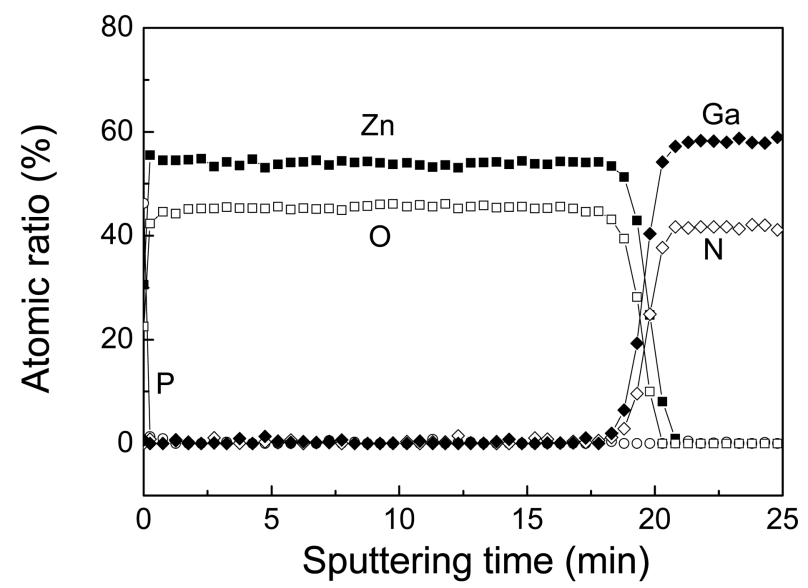

(b)

Fig. 2. AES depth profiles of $\mathrm{p}-\mathrm{ZnO}$ contacts to $p$-GaN before and after annealing at $700{ }^{\circ} \mathrm{C}$ for $1 \mathrm{~min}$ under a nitrogen ambient.

at a binding energy of $135.6 \mathrm{eV}$ is believed to come from $\mathrm{P}_{2} \mathrm{O}_{5}$ in the thin film. $\mathrm{P} 2 p$ core level peak regarding pure phosphorus state is normally observed at a binding energy of $130 \mathrm{eV}^{11)}$ As the annealing temperature increases, $\mathrm{P} 2 p$ core-level peak is shifted to the lower energy level which indicates that $\mathrm{P}$ and $\mathrm{O}$ atoms exchange the sites, resulting in the activation of $\mathrm{P}$ atoms for acceptors. $\mathrm{O} 1 s$ core-level peak at high energy side increased as annealing temperature increased. This result shows that the amount of loosely bound oxygen increased, which can compensate the formation of oxygen vacancies in $\mathrm{ZnO}$ during the annealing process. This is the mechanism for the activation of $\mathrm{p}$ $\mathrm{ZnO}: \mathrm{P}^{7)}$

To verify the increase in hole injection and current spreading by using IZO-based contact schemes, we fabricated LEDs with a dimension of $300 \times 300 \mu \mathrm{m}^{2}$. Fig. 3 shows the I-V characteristics of LEDs with different $p$ ohmic contacts. It can be seen that the forward voltage

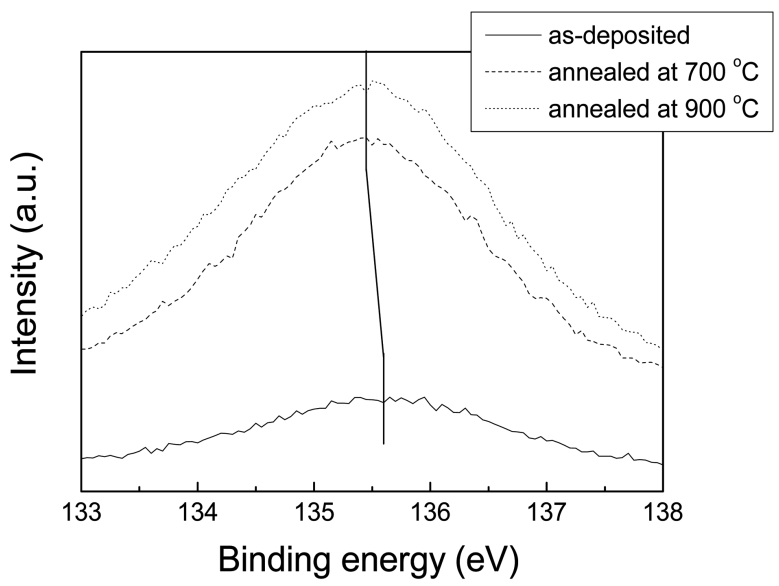

(a)

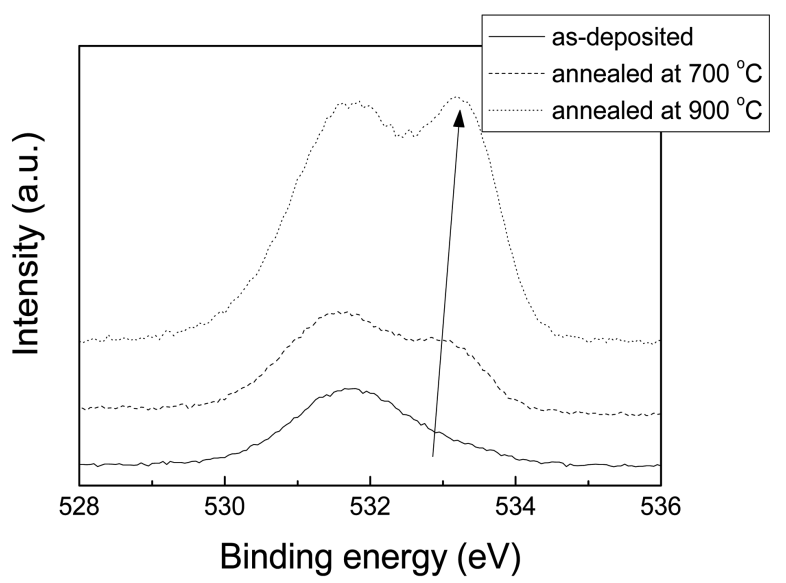

(b)

Fig. 3. (a) P $2 p$ core level peaks and (b) $\mathrm{O} 1 s$ core level peaks observed at the interface of $\mathrm{p}-\mathrm{ZnO} / \mathrm{p}-\mathrm{GaN}$ before and after different annealing processes under a nitrogen ambient.

measured at an injection current of $20 \mathrm{~mA}$ was $3.6 \mathrm{~V}$ and $5.9 \mathrm{~V}$ for $\mathrm{Ni} / \mathrm{Au}$ and $\mathrm{p}-\mathrm{ZnO}$ contacts to $p$ - $\mathrm{GaN}$, respectively. It is noteworthy that the forward voltage of the LED with a $\mathrm{p}-\mathrm{ZnO}$ ohmic layer was increased by $2.3 \mathrm{~V}$ compared to that of LEDs with standard $\mathrm{Ni} / \mathrm{Au}$ contacts. The series resistances of the LED with $\mathrm{Ni} / \mathrm{Au}$ and $\mathrm{p}-\mathrm{ZnO}$ contacts are 25.5 and $35.6 \Omega$, respectively. Even though the specific contact resistance of the annealed $\mathrm{p}-\mathrm{ZnO}$ contact is slightly higher than that of the $\mathrm{Ni} / \mathrm{Au}$ contact, the high forward voltage of GaN LED with $\mathrm{p}-\mathrm{ZnO}$ contact can be attributed to the high sheet resistance of $\mathrm{p}-\mathrm{ZnO}$ film and oxide formation on $\mathrm{p}-\mathrm{GaN}$ due to $\mathrm{Ar}$ ion bombardment effect during the deposition of $\mathrm{p}-\mathrm{ZnO}$.

In Fig. 4 the electroluminescence (EL) spectrums of LEDs prepared using the two different ohmic schemes, Ni/Au and $\mathrm{p}-\mathrm{ZnO}$, were shown with the injection current of $20 \mathrm{~mA}$ to make the same recombination of holes and electrons. The EL peak positions of both LEDs are the same of 


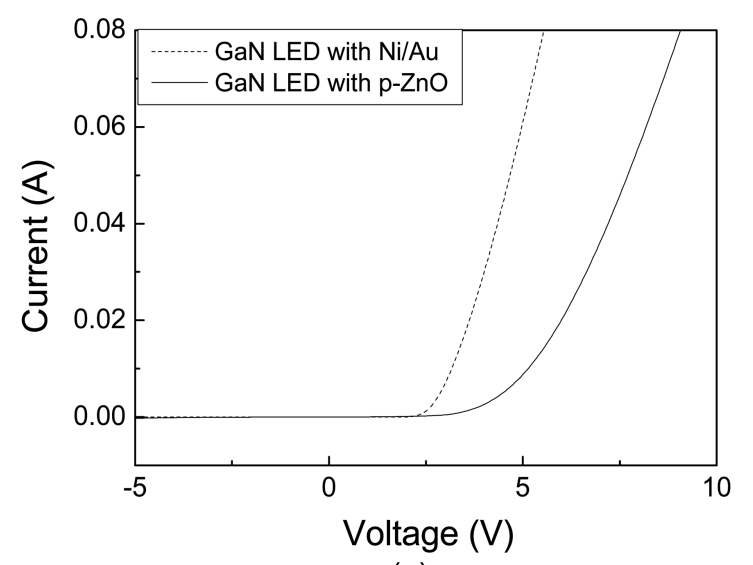

(a)

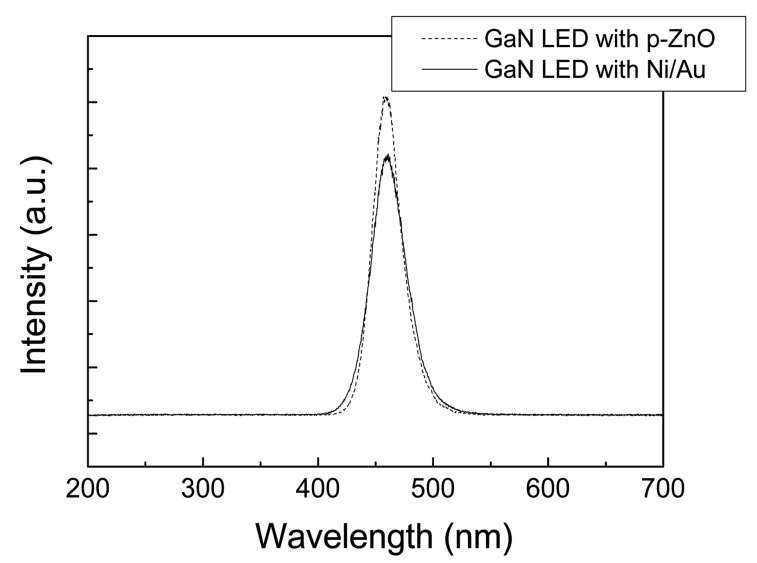

(b)

Fig. 4. (a) I-V curves and (b) EL spectrums of LEDs with conventional $\mathrm{Ni} / \mathrm{Au}$ and transparent $\mathrm{p}-\mathrm{ZnO}$ ohmic contacts.

$460 \mathrm{~nm}$. The light output power for LED with p-ZnO film was increased by $25.0 \%$ at $20 \mathrm{~mA}$ compared to that with $\mathrm{Ni} / \mathrm{Au}$ metal film. The light output powers are compared at the same injection current because the same recombination rate is achieved at the same injection current, resulting in the same amount of light generation in the devices. The light transmittances of the annealed $\mathrm{Ni} / \mathrm{Au}$ and $\mathrm{p}-\mathrm{ZnO}$ are 70.2 and $91.2 \%$, respectively. ${ }^{13)}$ The transmittance of $\mathrm{p}-\mathrm{ZnO}$ is $29.9 \%$ higher than that of $\mathrm{Ni} / \mathrm{Au}$, which is a little higher than the increase of output power, $25.0 \%$. This can be attributed that the higher voltage on GaN LED with p-ZnO might induce heating which can deteriorate the internal efficiency. The enhancement of light output power, however, could be attributed to the high light transmittance of the annealed $\mathrm{p}-\mathrm{ZnO}$ film compared to that of the $\mathrm{Ni} / \mathrm{Au}$ layer.

\section{Conclusions}

In summary, $\mathrm{p}-\mathrm{ZnO}$ ohmic scheme was investigated as highly transparent and ohmic contacts to $\mathrm{p}-\mathrm{GaN}$. The $\mathrm{p}-\mathrm{ZnO}$ contact, after annealing at $700{ }^{\circ} \mathrm{C}$ for $1 \mathrm{~min}$ in a nitrogen ambient, produced a low specific contact resistance of $7.82 \times 10^{-3} \Omega \cdot \mathrm{cm}^{2}$. The forward voltage and series resistance of GaN LED with p-ZnO increased possibly due to the poor current spreading and/or oxide formation during the deposition of $\mathrm{p}-\mathrm{ZnO}$. However, the light output power for LED with p-ZnO film was increased by $25 \%$ at $20 \mathrm{~mA}$ compared to that with $\mathrm{Ni} / \mathrm{Au}$ metal film. This is attributed to the high transmittance of $\mathrm{p}-\mathrm{ZnO}$ film.

\section{References}

1. S. J. Pearton, J. C. Zolper, R. J. Shul and F. Ren, J. Appl. Phys, Lett., 86(1), 1 (1999).

2. O. Ambacher, J. Phys. D, 31(20), 2653 (1998).

3. S. Nakamura, G. Fasol, The Blue Laser Diode, Springer, Berlin, (1997).

4. J. -K. Ho, C. -S. Jong, C. C. Chiu, C. -N. Huang, C. -Y. Chen, and K. -K. Shih, Appl. Phys. Lett., 74(9), 1275 (1999).

5. L. -C. Chen, J. -K. Ho, C. -S. Jong, C. C. Chiu, K.-K. Shih, F. -R. Chen, J. -J. Kai and L. Chang, Appl. Phys. Lett., 76(25), 3703 (2000).

6. R. -H. Horng, D. -S. Wuu, Y. -C. Lien, and W. -H. Lan, Appl. Phys. Lett., 79(18), 2925 (2001).

7. K. -K. Kim, H. -S. Kim, D. -K. Hwang, J. -H. Lim and S. -J. Park, Appl. Phys. Lett., 83(1), 63 (2003).

8. J. -H. Lim, C. -K. Kang, K. -K. Kim, I. -K. Park, D. -K. Hwang, and S. -J. Park, Advanced Materials, 18(20), 2720 (2006).

9. D.-J. Kim, Y. -T. Moon, K. -M. Song, and S. J. Park, Jpn. J. Appl. Phys. Part 1, 40(5A), 3085 (2001).

10. V. Srikant and D. R. Clarke, J. Appl. Phys., 83(10), 5447 (1998).

11. B. V. Crist, Handbook of Monochromatic XPS Spectrometer, Willy, New York, (2000).

12. J. -H. Lim, D. K. Hwang, H. S. Kim, J. H. Yang, R. Navamathavan, and S.-J. Park, J. Electrochem. Soc., 152(6), G491 (2005). 